\title{
Percepção dos idosos sobre grupos de terceira idade
}

\section{Edalys spercedtion of graps of eddely}

Resumo

O Brasil está envelhecendo, principalmente em consciência e participação, pois a cada dia aumenta o número de cidadãos preocupados com a saúde, com o crescimento cultural e que reivindicam mais espaço na sociedade. Entretanto, as transformações advindas do avanço tecnológico trouxeram uma expectativa de vida superior àquela esperada por muitos, e cada vez mais os idosos passam a somar uma porcentagem ainda maior, representando uma parcela significativa da população. O objetivo deste estudo foi identificar a percepção dos idosos sobre a participação nos grupos de convivência. Realizou-se entrevista com 20 pessoas, de ambos os sexos e divididas em dois grupos, das quais dez frequentam o Grupo Flor de Maçã, e dez frequentam o Grupo Melhor Idade em Ação. Os dados foram coletados através de entrevista semiestruturada e da observação participante registrada em diário de campo, que ocorreram em locais e horários agendados com os supervisores e participantes do estudo. Os dados foram analisados através das falas dos participantes, transformadas e separadas em categorias preestabelecidas. Verificou-se que a participação nos grupos trouxe grandes melhorias e mudanças na vida dos idosos participantes do estudo, podendo-se observar melhorias em diversos fatores como saúde, autoestima e valorização. Muitos relataram que as atividades realizadas nos grupos contribuíram bastante para o desenvolvimento das funções da vida diária, além de obter um reconhecimento e valorização, tanto pelos familiares como pela sociedade em geral. Conclui-se que a participação nos grupos é de suma importância na busca de se obter melhor qualidade de vida.

\section{Abstract}

Brazil is getting older, especially in awareness and participation, because every day increases the number of citizens concerned with health, with cultural growth and who claim more space in society. However, the changes resulting from technological advances have brought a life expectancy greater than that expected by many, and increasingly older people are now adding an even higher percentage, representing a
Palavras chave:

Envelhecimento da População. Grupos Etários. Idosos. Grupos de Convivência. Qualidade de Vida.

\footnotetext{
* Universidade do Oeste de Santa Catarina, Centro de Educação Letras e Educação Física. Videira, SC, Brasil.
} 
significant portion of the population. This study aimed to identify the perception of the elderly about participation in groups. Interviews were conducted with 20 people of both genders and divided into two groups, of which ten attended the Grupo Flor de Maçã, and ten attend the Grupo Melhor Idade em Ação. Data were collected through semi-structured interviews and participant observation recorded in a field diary, which occurred in places and times scheduled with supervisors and participants. The data were analyzed by the participants' speech, processed and separated into pre-established categories. It was found that participation in living groups made dramatic improvements and changes in the lives of elderly of the study and improvements in several factors can be noticed, such as health, self-esteem and recovery. Many reported that activities in groups contributed significantly to the development of the functions of daily life, besides getting a recognition and appreciation, both by families and by society in general. We conclude that participation in groups is paramount in the quest to achieve better quality of life.
Key words: Demographic Aging. Age Groups. Elderly. Living Group. Quality of Life.

\section{INTRODUÇÃO}

As questões associadas à velhice estão demandando com o tempo, atualmente são vários os esforços no sentido de manter o idoso inserido no meio social. Uma das formas de inserção da pessoa idosa na sociedade é através da formação de grupos de convivência, nos quais a pessoa desta faixa etária encontra espaço para desenvolver diversas atividades.

As mudanças que vêm ocorrendo na pirâmide populacional mostram que o número de pessoas com 60 anos ou mais está aumentando significativamente. No Brasil, nas décadas de 1950 e 1960, as taxas de crescimento anual da população mantiveram-se altas, mas a partir da década de 1970, essa taxa mostrou sensível redução, acentuando-se na década de 80. Simultaneamente, a distribuição etária da população brasileira se alterou. No início do século, os idosos constituíam apenas $3,3 \%$ da população, percentual que foi aumentando gradativamente, atingindo $4,1 \%$ em $1940,5,1 \%$ em 1970 e $6,1 \%$ em 1980 . O censo de 1991 mostrou que os idosos brasileiros já são $7,4 \%$ da população nacional. ${ }^{1,8}$

Vivemos numa sociedade que valoriza muito a juventude, a beleza, o "produtivo", e a velhice é uma fase da vida vista com preconceitos de inutilidade e dependência. Isto faz com que as pessoas idosas encontrem dificuldades de se inserir nesse meio. Diante dessas limitações, o idoso muitas vezes se isola, mesmo residindo com sua própria família, onde muitas vezes não possui poder de decisão, se sente sozinho, isolado em sua própria casa. Neste sentido, os "idosos têm a necessidade de participar de atividades de lazer para não se sentirem sozinhos".

Atualmente, múltiplas são as alternativas que buscam inserir esses indivíduos em diferentes espaços sociais, visando a uma melhor qualidade de vida e seu reconhecimento como cidadão. $\mathrm{O}$ crescimento do número de idosos vem trazendo enorme visibilidade perante a sociedade, porém a mesma precisa reformular sua concepção sobre velhice, para ampliar os recursos e oferecer aos idosos serviços que atendam a suas necessidades especificas.

A ideia que ainda persiste na sociedade sobre esta parcela da população é que ela não é produtiva e, portanto, não merecedora de preocupação social. Isso deve ser repensado para que o idoso ocupe seu espaço e posição perante a sociedade, "a participação dos idosos nos grupos de convivência leva a um aprendizado, uma vez que compartilham ideias, experiências, e também ocorre reflexão sobre o cotidiano da vida destas pessoas".

O convívio em grupos de convivência ou de idosos é um espaço importante para desencadear, tanto na pessoa idosa quanto na comunidade, uma mudança comportamental diante da situação de preconceito que existe nesta relação. Os grupos de convivência procuram fortalecer o papel social 
do idoso. Sendo assim, buscou-se através do presente projeto identificar a percepção dos idosos referente à participação em grupos de convivência da cidade de Friburgo - SC.

\section{METODOLOGIA}

O estudo é de natureza aplicada qualitativa e do tipo descritivo exploratório. O grupo de pesquisa foi composto por 20 pessoas, divididas em dois grupos, das quais dez participam de atividades no Grupo Flor de Maça e as outras dez participam de atividades no Grupo Melhor Idade em Ação, ambos situados na cidade de Fraiburgo, SC. Todos os pesquisados possuem idade superior a 60 anos e vêm participando semanalmente por um período de no mínimo dois anos de diferentes atividades dentro de seus respectivos grupos. Os dados foram coletados através de entrevistas semiestruturadas e observação participante realizadas com os 20 idosos.

As entrevistas foram realizadas entre os meses de agosto e setembro de 2008, através do prévio agendamento com os supervisores dos grupos de convivência e também com os entrevistados que já haviam sido informados sobre os objetivos do trabalho.
Antes de se iniciar as entrevistas foi lido um termo de consentimento e autorização, solicitando-se ao participante que o assinasse. Foi informado que os dados coletados seriam utilizados somente para fins científicos, e que o participante teria total acesso aos resultados da pesquisa depois de concluída.

Os dados foram coletados depois de os idosos terem realizado suas atividades diárias dentro do grupo. Os participantes selecionados foram convidados a permanecer no local para realizar a entrevista. As entrevistas foram gravadas em áudio tape, e os dados da observação registrados em diário de campo. Em seguida, os dados foram transcritos e separados em categorias durante a análise de dados.

Para a análise de dados, foram seguidos os seguintes passos: transcrição e leitura das informações e ordenamento dos dados, classificando-os em categorias que foram surgindo do campo a partir das respostas provindas dos idosos. A partir destas categorias, foram elaborados os quadros para melhor identificação e análise das categorias. Este trabalho foi aprovado pelo Comitê de Ética em Pesquisa CEP/ UNOESC/HUST, sob o parecer n ${ }^{\circ}$ 108/2008.

\section{APRESENTAÇÃO E DISCUSSÃO DOS RESULTADOS}

Quadro 1 - Razões que levam os idosos a participar dos grupos de convivência. Fraiburgo, SC, 2008.

\begin{tabular}{|l|c|c|}
\hline Razões & Porcentagem & Número de pessoas \\
\hline Melhoria na saúde & $45 \%$ & 9 \\
Melhoria na auto-estima & $25 \%$ & 5 \\
Orientação médica & $15 \%$ & 3 \\
Fazer novas amizades & $15 \%$ & 3 \\
\hline
\end{tabular}


O progressivo aumento da população idosa leva estudiosos da área a investigarem os meios de inserção dessa população na sociedade. À medida que os anos passam, o organismo humano sofre modificações significativas, a degenerescência orgânica se instala, os problemas de saúde aparecem e o idoso passa a enfrentar limitações na realização das atividades da vida diária.

O envelhecimento está associado a uma variedade de limitações físicas e psicológicas. Frequentemente isso torna difícil para os indivíduos desempenhar certas funções; dependendo de sua motivação, circunstâncias ambientais e reações à incapacidade, aqueles que são assim afetados podem também ficar inválidos. A consequência de tal invalidez é uma deterioração na qualidade de vida. ${ }^{4}$

A velhice é uma fase da vida na qual as patologias vão gradativamente ocorrendo. ${ }^{2}$ Visando a prolongar o tempo de vida com saúde, é necessário que o idoso se mantenha continuamente realizando atividades físicas e participando da vida social.

A busca por melhores condições de saúde é referendada pelos entrevistados deste estudo, como uma das razões que os levam a participar de grupos de terceira idade.

"Essa foi essa ginástica, essa aí foi uma grande coisa que eu comecei com a ginástica né, desde o primeiro dia que eles comecaram en já participei e vi que era uma coisa boa que ajudou muito como eu disse ali durante a primeira pergunta, foi uma...bom pras assim digamos circulações, nervos que tavam tudo meio enrolados, então ficou tudo muito bom né, eu acbo que foi a ginástica." (indivíduo n ${ }^{\circ} .01$ Grupo Flor de Maçã).

"Ah pra mim participar aqui foi, pra minha saúde foi muito bom, pra amizade, eu fiz muitas amizades, somos uma familia aqui, então eu pra mim melhorou muito isso ai, pra mim foi muito bom." 0 (indivíduo $n^{\circ} .01$ - Grupo Melhor Idade em Ação).

Outra razão mencionada se refere à necessidade de convivência grupal, característica de todo ser humano, a de estar inserido num grupo social, no qual possa interagir com outras pessoas.

"A amizade né, dai eu trabalbei 15 anos também como voluntária, dai fiz tudo aquela amizade, junto veio os exercícios tudo isso NE, que ajudou a gente NE, a continuar vindo." (indivíduo $\mathrm{n}^{\circ} .08$ Grupo Flor de Maçã).

"O encontro com todos, a amizade que a gente far, que a gente far. muito amigo aqui sabe então é importante, a gente sente saudades quando não pode vir NE, isso ajuda bastante e as atividades fisicas também, a caminhada tudo fazparte." (indivíduo n .02 - Grupo Melhor Idade em Ação).

Os idosos pesquisados apontam, também, que um dos motivos para iniciar sua participação nos grupos é a necessidade de realizar atividades físicas, sendo que estas geralmente são determinadas por orientação de médicos.

"É a saúde, fui recomendada pelo médico pra fazer algum tipo de atividade né e foi o que eu procurei e fez. eupersistir." (indivíduo $\mathrm{n}^{\mathrm{O}} .02$ - Grupo Flor de Maçã).

"Eu já fazia caminhada né, mas como me deu um infarto, o doutor disse que eu tinha que fazer exercicio diferente, daí uma amiga minha arrumou pra mim vim aqui, e eu comecei a vim aqui, mas olh a foi nota dez, mudou muito a minha vida porque eu tinha dificuldade para andar, pra conversar, e como mudou aqui fiz muita amizade." (indivíduo $\mathrm{n}^{\circ} .03$ Grupo Melhor Idade em Ação).

Percebemos que dentre os motivos apontados pelos idosos para frequentar os grupos de terceira idade, estão à melhoria da qualidade de vida, nos aspectos referentes à saúde física e mental. Buscam também aumentar o período de vida ativa, prevenindo perdas funcionais e recuperando capacidades.

"Olha, pra mim contribui em tudo né, porque eu melhorei, olha eu trabalhava assim, eu trabalhava quando era de tarde eu tava cansada, hoje não, hoje se forpreciso en trabalho o dia todo e me sinto muito bem." (indivíduo no. 02 - Grupo Flor de Maçã). 
"Ah, foi muito bom, foi bom porque eu tinha dificuldade e depois que eu vim aqui como mudou, é pra subir uma escada, épro meu trabalho da casa, foi ótimo." (indivíduo $\mathrm{n}^{\mathrm{o}} .03$ - Grupo Melhor Idade em Ação).

Ter um grupo de referência, no qual se possa compartilhar alegrias, tristezas, conhecimentos, entre outros, propicia ao idoso um suporte emocional e motivação para que este indivíduo tenha objetivos em sua vida.

Em estudo semelhante, Knoplich ${ }^{5}$ afirma que "a participação dos idosos nos grupos de convivência leva a um aprendizado, uma vez que se compartilham ideias, experiências, e também ocorre uma reflexão sobre o cotidiano da vida dessas pessoas”.

A possibilidade de ter um espaço no qual possa realizar diferentes atividades e, ao mesmo tempo, conversar, sorrir e estar com outras pessoas, é referido pelos entrevistados deste estudo como sendo um ponto positivo para os participantes. Tal situação favorece um aumento na autoestima, valoriza a pessoa e faz com que o idoso exerça sua cidadania.

"É, se sente assim até mais animado, a autoestima deles melhora bastante, a nossa quer direr, éisso aí." (indivíduo n ${ }^{\circ} .03$ - Grupo Flor de Maçã).

"A gente fica mais alegre, a gente fica mais disponivel, a gente querparticipar de mais coisas, e acho que é isso." (indivíduo $\mathrm{n}^{\circ} .04$ - Grupo Melhor Idade em Ação).

O idoso passa a participar do grupo por intermédio, incentivo ou convite de alguma pessoa, sendo estes médicos ou amigos ou familiares como relatam os indivíduos a seguir.
"A que mais me incentivou foi as próprias amigas né, que vinham me convidavam, já faziam muito tempo que me convidavam, e eu comecei a vir gostei e vi que há uma boa razão pra gente participar." (indivíduo n ${ }^{\circ} .04$ - Grupo Flor de Maçã).

"Olha, essa razão eu fui convidado para participar deste grupo aípra fazer um grupo de amigos, que nós temos o grupo de amigos né, isso aí foi muito bom pra nós aí, que a gente se conbece mais né, é uma coisa boa, a gente tem ai essas, a gente tem que ter umas atividades boas aí né, como as atividades de ginástica essas coisas aí, e nos temos a maioria de nosso grupo eles tem a pressão alta como é, a pressão alta, tem a diabete, tudo isso ai né, então é muito bom pra nós isso aí, a caminhada, a ginástica é muito bom, caminhada é bom que controla a pressão, pra diabete ela fortalece os ossos então é uma coisa muito boa mesmo pra nós isso aí." (indivíduo $\mathrm{n}^{\mathrm{O}} .08$ Grupo Melhor Idade em Ação).

Outros idosos, por sua vez, procuram o grupo espontaneamente, querendo fazer parte do mesmo, em geral por se identificarem com as atividades ali desenvolvidas.

"Primeiro en comecei a vim, dai en pedi pro men médico, ele disse que eu poderia vir, daí eu começei e tô até hoje." (indivíduo n ${ }^{\circ} .08$ - Grupo Flor de Maçã).

"Eu comecei vim porque en gosto da ginástica e da dança." (indivíduo n ${ }^{\circ} .10$ - Grupo Melhor Idade em Ação).

Ser convidado ou querer participar é uma das formas de acesso do idoso ao grupo, e independente de qual das vias é utilizada, percebemos que, ao iniciar as atividades, esses indivíduos geralmente gostam e passam a frequentar o grupo, tendo uma avaliação positiva em relação aos resultados proporcionados pelo grupo a suas vidas. 
Quadro 2 - Mudanças percebidas pelas pessoas após a participação no grupo. Fraiburgo, SC, 2008.

\begin{tabular}{|l|c|c|}
\hline \multicolumn{1}{|c|}{ Mudanças } & Porcentagem & Número de pessoas \\
\hline Conquistou novos amigos & $50 \%$ & 12 \\
Melhorou a saúde & $40 \%$ & 8 \\
Valorização & $10 \%$ & 2 \\
\hline
\end{tabular}

Outro fator importante observado nas falas está relacionado com o aumento das amizades. Este fator influencia bastante a continuidade dos idosos nos programas e nas mudanças positivas que ocorrem na vida dessas pessoas. Podemos identificar esta questão conforme aponta dois indivíduos, sendo um de cada grupo.

"Houve né bastante... a gente pega mais amizade com as pessoas que aqui estão né, então eu acho que é uma boa razão pra gente participar." (Indivíduo $\mathrm{n}^{\mathrm{o}} .04$ - Grupo Flor de Maçã.)

"Houve porque quando a gente fazessas atividades que se encontra aqui então, até na rua a gente se vê como irmãos, como amigos, então é uma coisa muito importante pra vida aqui e lá fora social né." (Indivíduo no. 02 - Grupo Melhor Idade em Ação).

O envelhecimento provoca alterações orgânicas, reduzindo a capacidade do idoso, impedindo-o de realizar atividades cotidianas. Ao frequentar o grupo de convivência, os entrevistados apontam que houve mudanças significativas em relação a sua saúde.

"Houve sim... melhorei bastante nas minhas dores muscular que eu tinha, foi excelente dor nos joelhos que eu tinha...e e isso aí foi ótimo para mim, olha hoje eu to praticamente quase curada." (Indivíduo $\mathrm{n}^{\mathrm{O}}$. 01 - Grupo Flor de Maçã).

"Muitas eu notei... mudanças no meu corpo né... bastante assim também e nossa eu consigo fazer caminhadas hoje em dia não me canso, como diz na quinta-feira a gente participa o dia inteiro, pela manha aqui, de tarde eu danco a tarde inteira ainda... é muito bom." (Indivíduo no 06 - Grupo Melhor Idade em Ação).
Desta forma, "uma das maneiras do individuo avaliar o seu estado de saúde é basear-se no seu desempenho próprio, ou seja, na sua capacidade de desenvolver suas atividades cotidianas". ${ }^{5}$ Frequentar um grupo de convivência significa encontrar um espaço em que se podem partilhar afetos (amor, amizade...) o que se reflete no relacionamento com a família e na disposição física.

A possibilidade de conhecer novas pessoas, construir amizades, viajar acompanhando o grupo, fazer exercícios físicos, divertir-se, dentre outras razões, são mudanças apontadas pelos entrevistados que os induzem a continuar participando do grupo e a estimular outras pessoas para que frequentem o grupo.

"Foi a ginástica e a dança e quando nos saímos nos grupos en era uma pessoa bastante fechada, hoje em dia eu sou uma pessoa mais alegre." (indivíduo $\mathrm{n}^{\mathrm{0}} .05$ - Grupo Flor de Maçã).

"Eu senti assim porque a gente quando vai nos outros lugares que sabem que a gente participa de um grupo assim da terceira idade, é muito bom eles verem a gente com outros olhos, novas amizades perguntam como que é aqui, é um negocio muito bom, então é nota dez:" (indivíduo $\mathrm{n}^{\mathrm{o}} .03$ - Grupo Melhor Idade em Ação).

A partir da concepção de que a terceira idade é uma etapa de independência, maturidade e tempo de usufruir atribuições ligadas ao dinamismo, à atividade, ao lazer, os idosos passam a invadir progressivamente os espaços públicos, criando estratégias de sociabilidade que lhes permitem tecer novas relações sociais e fugir do isolamento. ${ }^{5}$ 
Nas falas a seguir, constatam-se as mudanças que ocorreram na vida das pessoas idosas deste estudo, relacionadas ao humor, timidez e facilidade em manter diálogo com as outras pessoas.

"Houve bastante amizade né, melhora nos exercícios, a timidez, a valorização né que a gente tem mais valorização, tudo isso". (indivíduo n ${ }^{\circ} .09$ Grupo Flor de Maçã).
"A gente fica mais alegre, a gente fica mais disponivel, a gente quer participar de mais coisas, e acho que é isso." (indivíduo n ${ }^{\circ} .04$ - Grupo Melhor Idade em Ação).

Enfim, percebe-se que ao frequentar os grupos, os idosos adquirem conhecimentos, encontram uma variedade de práticas sociais e exercitam uma gama de sentimentos e sensações que ainda desejam viver.

Quadro 3 - Atividades proporcionadas pelos dois grupos de idosos. Fraiburgo, SC, 2008.

\begin{tabular}{|c|c|}
\hline Grupo Flor de Maçã & Grupo Melhor Idade em Ação \\
\hline Ginástica Localizada e Aeróbica & Ginástica Localizada e Aeróbica \\
Atividades Recreativas/ Jogos de Mesa & Atividades Recreativas/Jogos de Mesa \\
Palestras Preventivas & Palestras Preventivas \\
Aulas de Dança/ Tardes Festivas & Aulas de Artesanatos/ Manhas Festivas \\
Caminhada/ Aulas de Step & Caminhada Orientada/Jogos Desportivos \\
Viagens e Excursões & Viagens e excursões \\
\hline
\end{tabular}

A chegada à terceira idade traz algumas limitações sobre um corpo já muito vivido; nessa fase já não se tem a mesma vitalidade, a mesma rapidez nos movimentos, o mesmo raciocínio rápido e a mesma coordenação motora da época da juventude.

O tempo que antigamente era transformado em trabalho hoje se torna disponível à procura de ocupações, e na maioria das vezes os idosos não sabem o que fazer para ocupar o tempo livre. Diante disto, surgem os centros de convivência para terceira idade como um lugar onde os idosos têm oportunidade de realizar diferentes atividades, ocupando o tempo livre.

Além de procurar ocupar seu tempo livre, a grande maioria dos idosos busca, com a participação nesses grupos, realizar atividades que possibilitem obter melhorias principalmente na questão da saúde, o que isto pode ser identificado nas falas seguintes.
"Muitas coisas boas me trouxeram, né, por exemplo, na ginástica né foi uma coisa que ajudou bastante por motivo de muitas dores que eu tinha no corpo, então isso aí foi excelente, uma grande coisa que podia acontecer, gostei muito." (indivíduo $\mathrm{n}^{\mathrm{O}} .01$ Grupo Flor de Maçã).

"Contribui muito, viu?, porque é muito importante a ginástica, a gente se sente melhor fica mais fácil pra subir escadas, pro trabalho caseiro e mesmo pros trabalhos na sociedade, na comunidade que eu faço muito trabalho na comunidade, né, isto me facilitou bastante." (indivíduo $\mathrm{n}^{\mathrm{o}} .02$ - Grupo Melhor Idade em Ação).

A participação dos idosos nestes grupos, nos quais desenvolvem várias atividades, leva à construção de uma utopia de envelhecer saudável, pois após entrarem em algum grupo, observamse as mudanças na vida dessas pessoas, em relação à vida cotidiana, alimentação, suas atividades motoras e intelectuais. ${ }^{6}$ 
$\mathrm{Na}$ busca de obter melhorias na saúde, tem-se como fator importante o cuidado com a alimentação e a prática de atividades físicas. $\mathrm{O}$ grupo traz isso ao idoso através de palestras educativas: aprende-se quais alimentos deve comer, e isso, aliado à prática de atividades oferecidas dentro dos grupos, permite que a grande maioria identifique mudanças, principalmente na sua saúde.

Ainda em relação a isto,se pode observar que a prática de exercícios contribui bastante para a realização dos afazeres domésticos, o que pode ser observado nas falas a seguir.

"Bom pra mim foi muito bom, porque desenvolve o próprio serviço na casa, desenvolve mais rápido, não sinto mais aquela canseira, que qualquer coisa que a gente faria ficava cansada, ficava como que a gente diz assim praticamente entrevada, né, porque se você não faz um exercício, não faz nada você comeşa a ficar entrevada né."(indivíduo n ${ }^{\circ} .04$ - Grupo Flor de Maçã).

"Olha de muitas formas, eu não conseguia mais quase assim, só cuidava da casa, só dona de casa, não conseguia mais pendurar uma roupa no varal, me doía muito meus braços, né, e depois das atividades nossa é surpreendente eu consigo fazer todo o serviço, consigo vim nas minhas atividades, foi muito bom para mim." (indivíduo n ${ }^{\circ} .06$ - Grupo Melhor Idade em Ação).

Diante desses fatores, percebe-se a importância que os grupos exercem na vida destas pessoas, pois ali o idoso tem a possibilidade de encontrar estimulo para uma vida social sadia, desenvolver sua cultura e ter momentos de lazer. Melhoramse, assim, sua autoestima e sua aceitação na sociedade, pois é nesses locais que aprendem lições de cidadania, de participação e de como colaborar para o bem comum, aprendendo que para exercêlas não há limite de idade.

Enfim, é o que se pretende nesses grupos de terceira idade: o simples fato de sair de casa, encontrar pessoas em condições iguais, manter conversas sobre vários assuntos, distrair-se com novidades, movimentar-se em atividades físicas, são de fato mecanismos capazes de fornecer ao processo de envelhecimento mais prazer, qualidade e dignidade.
Acompanhando as atividades desenvolvidas nos grupos, observa-se o surgimento das confraternizações, festividades e bailes realizados pelos mesmos. Nesses eventos, os participantes estabelecem relações com o sexo oposto, exercem sua vida social, comunicando-se e interagindo com os demais e com pessoas de outras faixas etárias também. Além disso, tais festividades não deixam de oferecer um lugar onde os idosos praticam exercícios físicos, dançando e indo ao encontro dos benefícios para sua faixa etária. ${ }^{7}$ Através de seus coordenadores, os grupos realizam o trabalho de socialização, sobretudo nos trabalhos sociais e nas excursões para outras cidades, onde os idosos recebem a oportunidade de compartilhar informações, curiosidades e conhecimentos com pessoas novas.

Em relação aos grupos estudados nesta pesquisa, podemos observar que os dois seguem os mesmos objetivos e quase as mesmas formas de trabalho; o que muda um pouco entre um e o outro são as atividades proporcionadas pelos mesmos.

O grupo Flor de Maçã disponibiliza seu espaço e atividades ao pessoal que reside mais ao centro da cidade; possui um professor de Educação Física que trabalha com toda a parte da recreação, além de jogos de mesa e de ginástica localizada e aeróbica. Os idosos que frequentam este grupo participam também das quintas-feiras de tardes festivas, que incluem os tão aguardados bailes.

O grupo Melhor Idade em Ação disponibiliza seu espaço e atividades ao pessoal que reside mais no interior da cidade; possui dois professores, sendo uma professora pedagoga que trabalha toda a parte de palestras a trabalhos em sala, incluindo artesanatos. Já o professor de Educação Física trabalha toda a parte recreativa, jogos de mesa, caminhadas orientadas, ginástica localizada e aeróbica, além de encontros festivos para comemorar os aniversários dos frequentadores.

Como pode ser visto, os grupos em si realizam praticamente as mesmas atividades, sendo que as atividades trabalhadas possuem um único objetivo, que é auxiliar na melhoria da qualidade de vida das pessoas que dali participam. 
Aolongo do tempo, observa-se o reconhecimento da importância e da exigência de estudos sobre a terceira idade, uma vez que o percentual aumenta paulatinamente comparado com o número da população. Trata-se de um contingente populacional que possui experiência de vida, qualificação e potencialidade a oferecer à sociedade.

A imagem que possuímos dos idosos vem mudando devido ao avanço das tecnologias na área da saúde, proporcionando elevação $\mathrm{da}$ expectativa de vida: o novo idoso é influenciado por hábitos saudáveis. Não é apenas com a saúde física que o idoso está mais cuidadoso, ciente de que o corpo e a mente estão muito associados, ele busca manter ambos em atividade.

\section{CONCLUSÃO}

Os chamados "programas de terceira idade" oferecem diferentes propostas para lazer e ocupação do tempo livre; , são espaços nos quais o convívio e a interação com e entre os idosos permitem a construção de laços simbólicos de identificação, e onde é possível partilhar e negociar os significados da velhice, construindo novos modelos, paradigmas de envelhecimento e construção de novas identidades sociais.

Em relação a esta pesquisa, podemos verificar que os grupos ou os programas para terceira idade

\section{REFERÊNCIAS}

1. Anderson MIP. Depressão. In : Caldas CPA. Saúde do idoso: a arte de cuidar. Rio de Janeiro : UERJ; 1998. p. 78-83.

2. Barbosa M. Idoso, mas saudável. In: http:// blog.bolsademulher.com/MarcelloBarbosa/ 2008/06/08/Idosos_mas_saudaveis/2008. acesso em mar. 2008.

3. Campos CMT. Caminhos de envelhecer. Rio de Janeiro: Revinter; 1994. p.67

4. Matsudo SM. Envelhecimento e atividade física. Londrina: Midiograf; 2001, p.49. representam muito para as pessoas idosas. Pode-se verificar que a participação nos grupos contribui em diversos fatores aos nossos entrevistados. Com esta pesquisa, pudemos identificar que a grande maioria dos entrevistados procurou os grupos com o objetivo único de obter melhoras em sua saúde. Alguns iniciaram a participação por conta própria, já outros receberam influências principalmente de seus médicos e familiares. Também houve os que procuraram os grupos com o objetivo de conhecer novas pessoas, pois se sentiam muito sozinhos, e após frequentar os grupos, os idosos relataram mudanças significativas, sobretudo na questão da autoestima.

As mudanças, segundo nossos entrevistados, atingiram principalmente os fatores que se relacionam com a questão da saúde, sendo que muitos relataram que, antes de frequentar os grupos, viviam com dores que os impossibilitavam de realizar atividades comuns da vida diária. As atividades proporcionadas pelos grupos auxiliaram muito para que os idosos deste estudo pudessem obter um estilo de vida mais saudável e, consequentemente, uma melhora na qualidade de vida.

Concluímos que a participação nos grupos é de suma importância para a população idosa, fato que pode ser constatado neste estudo. Verificamos que a grande maioria de nossos entrevistados identificou mudanças favoráveis que fizeram com que obtivessem uma melhor qualidade de vida.
5. Knoplich J. Osteoporose, o que você precisa saber. 3. ed. São Paulo: Robe Editorial; 2001. p. 79.

6. Osorio LC. Grupos, teoria e prática: acessando a era da grupalidade. Porto Alegre: Artes Médicas; 2000. p. 93.

7. Peixoto C. De volta às aulas ou de como ser estudante aos 60 anos. In: Veras R P.Terceira idade: desafios para o terceiro milênio. Rio de Janeiro: Relume-Dumará; 1997. cap. 2, p.41-74.

8. Papaléo Netto M. Gerontologia: A velhice e o envelhecimento em visão globalizada. Rio de Janeiro: Atheneu; 1996. p.36. 
